\title{
Políticas públicas e formação humana: contribuições para o futuro
}

Eloiza Oliveira, Floriano Godinho de Oliveira e Luiz Antonio Saléh Amado (orgs.)

\section{(2) OpenEdition}

1 Journals

Edição electrónica

URL: http://journals.openedition.org/espacoeconomia/7945

DOI: 10.4000/espacoeconomia.7945

ISSN: 2317-7837

Editora

Núcleo de Pesquisa Espaço \& Economia

Refêrencia eletrónica

Eloiza Oliveira, Floriano Godinho de Oliveira e Luiz Antonio Saléh Amado (orgs.), « Políticas públicas e formação humana: contribuições para o futuro », Espaço e Economia [Online], 15 | 2019, posto online no dia 02 novembro 2019, consultado o 05 novembro 2019. URL : http://journals.openedition.org/ espacoeconomia/7945; DOI : 10.4000/espacoeconomia.7945

Este documento foi criado de forma automática no dia 5 novembro 2019.

(C) NUPEE 


\section{Políticas públicas e formação humana: contribuições para o futuro}

Eloiza Oliveira, Floriano Godinho de Oliveira e Luiz Antonio Saléh Amado (orgs.)

\section{Editora Consequência}

1 Políticas públicas e formação humana: contribuições para o futuro / organizado por Eloiza Oliveira, Floriano Godinho de Oliveira, Luiz Antonio Saléh Amado. - Rio de Janeiro : Consequência, 2019.

\section{Link para a EDITORA CONSEQUÊNCIA}

2 http://www.consequenciaeditora.net.br/p-11200349-POLITICAS-PUBLICAS-EFORMACAO-HUMANAContribuicoes-para-o-futuro.-Org.Floriano-Godinho;-Luiz-Salehe-Eloiza-Oliveira 
Capa

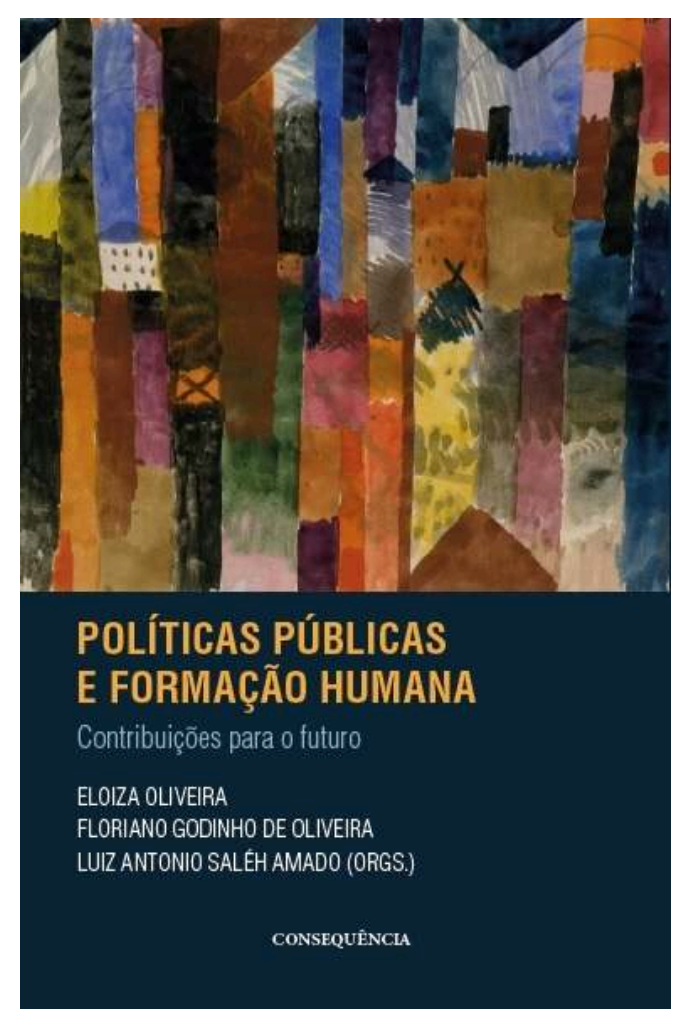

\section{Apresentação do livro}

Trazemos à luz uma coletânea de textos que tem como cenário de produção o Programa de Pós-Graduação em Políticas Públicas e Formação Humana da Universidade do Estado do Rio de Janeiro (PPFH/UERJ), seus professores, autores dos capítulos, as pesquisas e atividades acadêmicas que desenvolvem.

4 Um programa de pós-graduação ganha vida e existência acadêmica concreta por meio do pensamento e das pesquisas dos professores e estudantes que os compõem. Trazer a público essa produção aproxima o Programa da população e aumenta o sentimento de pertença de todos que dele fazem parte.

5 Nosso Programa destina-se à produção de conhecimentos e à formação humana, em caráter interdisciplinar, relativos às políticas públicas e à formação humana, e isso está expresso nos ensaios e relatos de pesquisas que o leitor encontrará.

Conhecer os dois eixos organizadores do Programa permite perceber o envolvimento ideológico e as escolhas políticas dos que aqui apresentam seus artigos. Na direção oposta das instituições de ensino que dão suporte ao capitalismo e que objetivam "fornecer conhecimentos e o pessoal necessário à maquinaria produtiva em expansão do sistema capitalista, mas também gerar e transmitir um quadro de valores que legitima os interesses da classe dominante" (MÉSZÁROS, 2005, p. 15), ${ }^{1}$ o PPFH busca a construção de cidadãos críticos e comprometidos com a realidade social do nosso tempo. Desenvolve a formação humana que freireanamente podemos chamar de libertadora e que não é alcançada "pelo acaso, mas pela práxis de sua busca; pelo conhecimento e reconhecimento da necessidade de lutar por ela" (FREIRE, 2005, p. 34). ${ }^{2}$ 
7 A outra linha de pesquisas do PPFH, também aqui representada, é a de políticas públicas. Por meio da leitura dos capítulos que a ela se referem, o leitor verá que essas políticas não são entendidas como acumulados de códigos e legislações. O PPFH mergulha na análise crítica das mesmas em todo o seu ciclo de geração, implementação, monitoramento e avaliação.

Identifica a organização e integração dos elementos teóricos e conceituais que lhes dão origem, assim como a vinculação que apresentam (ou não) com um "problema público" e com o bem público a que estão referidas. Analisa a relação entre as políticas de Estado, que independem dos governos e estão amparadas pela Constituição, e as políticas de governo, que dependem da alternância de poder. Verifica, em profundidade, qual a participação de atores dos diversos setores da população nesse processo de formulação de políticas e a existência ou não de verticalizações de matiz autoritário e de privilégio de interesses hegemônicos na gestação das mesmas.

9 Segundo Dias e Matos (2012), a participação dos atores políticos na formulação das políticas públicas é determinada pelo funcionamento das instituições políticas e das regras institucionais mais básicas que determinam os papéis de cada um.

10 Fazendo um breve histórico do nosso Programa, podemos dizer que o PPFH, criado em 2005, é idealizado fazendo jus à Universidade que o abriga. A Universidade do Estado do Rio de Janeiro destaca-se, entre as IES públicas brasileiras, pela vocação muito específica que assumiu de atendimento às demandas regionais e de aguçada sensibilidade ao contexto social. No âmbito do Rio de Janeiro e até mesmo do país, esse pioneirismo foi ilustrado pelo fato de que a UERJ assegurou, por muitos anos, a única oferta de cursos noturnos da região e por ter sido a primeira instituição a aderir ao sistema de cotas, atraindo um perfil de discente muito próprio e incomum nas IES.

11 O PPFH herda, ainda, a vitalidade do Laboratório de Políticas Públicas/LPP (2000), sua forte tradição no desenvolvimento de atividades de pesquisa, análise e apoio às políticas públicas de caráter democrático. Em síntese, a breve história do PPFH atesta a culminância de uma atuação institucional que, expressando um dos aspectos mais centrais da identidade da UERJ, está registrada sob a forma de pesquisas, publicações, intercâmbios e atuação concreta na realidade regional e nacional, capazes de aliar a efetivação de condições adequadas à reflexão e ao aprofundamento teórico ao desenvolvimento de novas práticas de formação em nível de pós-graduação e de intervenção social.

12 Nesse sentido, a implantação do PPFH se reveste de caráter bastante promissor, consentâneo com os anseios da comunidade acadêmica e coerente não só com a história da instituição que o abriga, bem como com a trajetória dos componentes institucionais e da equipe envolvida - formada por pesquisadores com longa experiência em pósgraduação e pesquisa.

13 Para apresentar os capítulos, precisávamos de um eixo articulador que desse sentido a essa apresentação, uma "linha de costura", ou melhor, de bordado, que criasse a tapeçaria colorida de matizes e tons que constituem uma coletânea.

Onde buscar esse eixo???

Optamos pela poesia, em nada incompatível com a ciência e a produção do conhecimento a ela concernente.

16 Encontramos o rumo buscado no poeta, escritor e ensaísta uruguaio Mario Benedetti, profundamente envolvido com as questões políticas do seu país, e que foi obrigado a 
abandonar o Uruguai após o golpe militar de 1973. No exílio, morou em diversos países (Argentina, Peru, Cuba) até chegar à Espanha. Retornou a Montevidéu após dez anos, e a experiência do exílio político influenciou muito a sua obra.

17 Escolhemos, então, para a cerzidura desta apresentação, o poema "Por que cantamos?".

${ }^{3}$ A apresentação do pensamento e do trabalho desenvolvido pelo PPFH é, a seu modo, um canto de liberdade e de fé no futuro, constituído pelos mestres e doutores que formamos, pelo conhecimento científico que produzimos. Como dizia o poeta, "só quando transgrido alguma ordem o futuro se torna respirável".

Vamos escandir as estrofes do poema, intercalando-os com a apresentação dos capítulos que constituem a obra.

Assim começa Benedetti, com uma descrição de cenário preocupante:

Se cada hora vem com sua morte

se o tempo é um covil de ladrões

os ares já não são tão bons ares

e a vida é nada mais que um alvo móvel

Com esse mote, sugerimos a leitura do capítulo escrito pelo nosso saudoso Theotônio dos Santos, "Hipóteses sobre a conjuntura mundial depois do 11 de setembro". Em seu texto, Theotônio dos Santos propõe uma vigorosa e inovadora reflexão sobre a necessidade de que a sociedade mundial passe "a um nível mais alto de civilização". 0 autor ainda realiza uma importante análise das crises econômicas no início do século XXI, em que a estrutura da crise de 2008 foi sendo mostrada, revelando a incapacidade do sistema capitalista de produzir novas formas de relações sociais de produção a partir dos imensos avanços da revolução científico-técnica no mundo contemporâneo. Neste cenário, se intensificam as estratégias geopolíticas dos EUA e um retorno ao imperialismo e às práticas terroristas pelas forças militares norte americanas nas regiões petrolíferas, que se tornam alvos de interesses da dominação americana. Tudo isso sob um infame domínio e restrição de informações livres, hoje dominadas por agências de notícias completamente atreladas aos projetos neoliberais. Theotônio conclui mostrando que as formas de enfrentamento das crises pela via do triunfo ideológico do neoliberalismo e a imposição de políticas por ele inspiradas na maior parte dos países no mundo levaram a humanidade à crise mais profunda em toda a sua história.

\section{O poeta continua...}

você perguntará por que cantamos cantamos porque o rio está soando e quando soa o rio / soa o rio

O soar do rio nos faz ouvir e pensar em aspectos importantes da vida do homem, como o trabalho, a saúde e as políticas públicas que lhes dão suporte e sobrevivência digna.

Isso nos remete a um novo bloco de três capítulos. No primeiro, "Trabalho, educação e saúde: dimensões de uma trajetória de pesquisa", Marise Ramos apresenta sua trajetória como pesquisadora na área de educação dos trabalhadores, articulando conhecimentos com a política de formação de trabalhadores da saúde, particularmente as conduzidas no âmbito das Escolas Técnicas do Sistema Único de Saúde (ET-SUS). Neste sentido, a autora discute a convergência entre sua trajetória de pesquisa e o contexto contemporâneo das políticas de educação de trabalhadores em geral e da área da saúde, em particular, no Brasil. 

trabalho e a saúde das trabalhadoras e dos trabalhadores", Katia Santorum e Hélder Muniz apresentam a importância da análise clínica do trabalho enfocando sua contribuição às intervenções e pesquisas em situações de trabalho, as quais visam a ampliação do poder de agir dos coletivos de trabalhadores e das suas lutas pelo fortalecimento das políticas públicas de saúde e educação. Nesse âmbito, destacam particularmente a perspectiva ética e epistemológica da ergologia e a abordagem teórico-metodológica da Clínica da Atividade, afirmando a potencialidade dessa perspectiva e dessa abordagem para um encaminhamento da relação entre as pessoas e o trabalho, em que a atenção está voltada para os engajamentos no trabalho pela via da criação e da saúde. para a análise de políticas públicas", analisa as relações históricas entre as delimitações territoriais pelos estados e o domínio sobre as populações que realizam as atividades produtivas e de organização da vida cotidiana. Estado, território e população, portanto, constituem uma tríade a partir da qual se desvelam a importância da compreensão das formas como o território é apropriado e usado no processo produtivo e social, para debater as possibilidades de realização das políticas públicas.

Parodiando o poeta, há uma pergunta que se impõe:

você perguntará por que cantamos

se nossos bravos ficam sem abraço

a pátria está morrendo de tristeza

e o coração do homem se fez cacos

antes mesmo de explodir a vergonha

Embalados por este trecho do poema, surge o texto de Esther Arantes e Eliana Oliveira, "Fome de justiça: anotações sobre a greve de fome. Brasília - DF: 31/07 a 25/09 de 2018". As autoras nos trazem a história da greve de fome realizada por um grupo de militantes de vários movimentos sociais, cujo objetivo era denunciar a arbitrariedade da prisão do ex-presidente Luiz Inácio Lula da Silva, bem como a fome e o sofrimento de parte significativa da população brasileira. Diante do silêncio da maior parte da mídia hegemônica brasileira, as autoras resolveram contar esta história a partir de um outro olhar.

Voltando a Benedetti,

você perguntará por que cantamos

se estamos longe como um horizonte

se lá ficaram as árvores e céu

Nesse triste contexto, uma série de mudanças inerente à perda do estado de direito e da democracia sem impuseram. Uma delas é contemplada pelo texto de Deise Mancebo, "A contrarreforma trabalhista no pós-golpe de 2016 no Brasil", que discute os impactos da contrarreforma para os trabalhadores, alertando para o fato de que os dilemas do trabalho no País encontram-se absolutamente imbricados com a complexa conjuntura econômica e política vivida no Brasil.

30 A Lei da Terceirização, da Reforma Trabalhista, objetiva aprofundar os mecanismos de uma economia baseada na espoliação. A modificação apressada da CLT, pelo Congresso brasileiro, significa o desmanche do polo protetivo trabalhista. De acordo com a autora, a contrarreforma trabalhista parece ter vindo para ficar por algum tempo e exigirá 
muita resistência e lutas da parte dos trabalhadores para que suas consequências sejam minimizadas e para que seu aparato legal seja estruturalmente modificado.

31 Ainda...

se cada noite é sempre alguma ausência

e cada despertar um desencontro

Mas existe uma tênue esperança delineada por dois textos. $O$ primeiro trata da resistência que pode ser estabelecida pela mídia, de Heliana Conde e Rosimeri de Oliveira Dias, "Foucault, inimigo do rei: a imprensa nanica brasileira como resistência", que afirma que, em suas estadas no Brasil durante a década de 1970, Michel Foucault foi sempre acompanhado pela imprensa nanica - adjetivo que condensa, em um único termo, duas características presentes em uma série de publicações brasileiras de então: o formato tabloide e a luta contra o controle da informação exercido mediante censura. O texto aprecia momentos, estilos e efeitos dessa interlocução entre a imprensa nanica e o filósofo francês, especialmente via 0 inimigo do Rei, jornal anarquista baiano em que tiveram enorme destaque temas como a homossexualidade, as drogas e a prisão. Se tais temas são ainda controversos na realidade brasileira, o texto assinala que o tom radicalmente libertário de 0 inimigo do Rei, muito apoiado no pensamento de Foucault, provocou inúmeras polêmicas também à época, inclusive entre os próprios anarquistas.

O segundo tem como foco o conhecimento como alavanca de transformação, no escrito de Antonio Carlos Ritto, "Produção de conhecimento socialmente robusto para intervenção local e criação de trabalho e renda". Este nos alerta que, na crise de fragmentação que enfrentamos, podemos ver uma consequência do privilégio da racionalidade científica com vocação para a análise e para a busca permanente das relações de causa e efeito, em detrimento da vocação para a síntese, própria dos sentimentos humanos excitados pelos contextos e comprometidos com a cultura e com saberes locais, não formais, que não se sustentam em relações de causa e efeito, mas em totalidades, em emergências. Para que seja produzido conhecimento socialmente robusto, Ritto propõe uma metodologia para intervenção em contextos reais cujas bases sejam sustentadas tanto pelo conhecimento científico quanto pelos conhecimentos tradicionais, próprios do local da intervenção, buscando formular propostas e estabelecer objetivos que respeitem constrangimentos do local e aproveitem oportunidades que este mesmo local disponibiliza.

Tenham certeza os que nos leem:

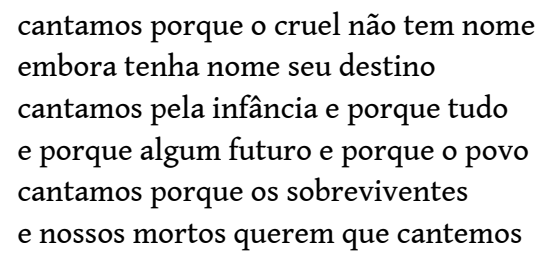

São vitimados os jovens, as minorias, as famílias, as instituições democráticas...

Essas denúncias estão explicitadas nos capítulos escritos por Estela Scheinvar, "As relações familiares em tempos de judicialização da vida", e por Raquel Villardi e Zacarias Gama, "Políticas de educação no Brasil hoje: o desmonte do Direito".

o primeiro nos alerta que, como efeito de um modo de organização social sustentado em relações de disciplinarização, a vida judicializada dá intensidade a práticas punitivas, assentadas na normalização e na moralização que compõem o discurso da lei e estruturam a lógica penal. Ao pensar o trabalho institucionalizado com famílias, os 
assujeitamentos que pautam as práticas profissionais emergem para além da obediência legal, desenhando os campos de força que convidam a potencializar as resistências à padronização judiciária.

Raquel Villardi e Zacarias Gama afirmam que políticas públicas são conjuntos de planos e ações desenvolvidos pelo Estado, de modo a assegurar um direito do cidadão. Resultam da disputa entre os diversos grupos ou segmentos da sociedade que buscam defender (ou garantir) seus interesses. Assim, a legislação que expressa os direitos do cidadão reflete a visão de futuro que o grupo hegemônico tem em determinado momento. No estudo empreendido neste texto, analisam a macrolegislação educacional, comprovando que o aparato legal criado a partir do século vem sendo desmontado, provocando a supressão dos direitos conquistados àquela altura.

cantamos porque o grito só não basta

e já não basta o pranto nem a raiva

cantamos porque cremos nessa gente

e porque venceremos a derrota

Não há como vencer a derrota e lutar contra uma realidade opressora, impeditiva da democracia e da equidade, a não ser suplantando a desigualdade e praticando a convivência cidadã com a diversidade.

Auxilia em muito essa vitória a reflexão trazida por dois capítulos dos nossos autores. No texto "Feminismos e multiplicidades: um olhar com a produção cultural de mulheres na periferia", Giovanna Marafon experimenta aproximações teóricas com feminismos contemporâneos ao fazer uma escolha pela multiplicidade de referências situadas a partir de um problema abordado há décadas por pesquisadoras e ativistas feministas negras brasileiras: sexismo e racismo, em intersecção. Trata-se fundamentalmente de um olhar que o campo da pesquisa, na produção cultural de mulheres na Baixada Fluminense, fez aparecer para a investigação ao definir sua atuação como movimento feminista e antirracista. Apresenta algumas das questões vitais elencadas pelo coletivo de mulheres produtoras culturais em sua luta por direitos e constrói interrogações sobre o duplo movimento de criar e produzir na cultura e a si mesmas, com vistas a um possível diálogo entre uma estética da existência e os feminismos.

41 No texto "Memórias, corpos, músicas e saberes moventes da diáspora africana no Rio de Janeiro", Denise Barata nos fala da diáspora africana, um dos maiores deslocamentos populacionais da história da humanidade, destacando o intenso trânsito simbólico e o estabelecimento de uma cultura cheia de similaridades nas Américas. Com seu texto, a autora procura contribuir para os estudos das culturas musicais africanas e de seus desdobramentos no movimento da diáspora, propondo uma reflexão sobre as possibilidades de manutenção, difusão e visibilização de práticas e de espaços de construção de conhecimento que consideram e valorizam uma outra forma de pensar o mundo.

Benedetti continua, em sua bela e contundente poesia...

cantamos porque o sol nos reconhece

e porque o campo cheira a primavera

e porque nesse talo e lá no fruto

Esses acenos estão em um bloco de capítulos referentes à relação das políticas públicas, como as cotas, com a educação, à formação de professores e às tecnologias aplicadas à construção da subjetividade e do conhecimento. 
Chegando ao final da obra, temos acenos de futuro por meio de temas relacionados à educação.

Este bloco é formado por quatro capítulos: "Diálogos e interfaces das políticas sociais com a educação pública", de Eveline Algebaile e Ney Luiz de Almeida; "Cotas para alunos oriundos da rede pública de ensino e para pretos e pardos", de Gaudêncio Frigotto; "Práticas pedagógicas e avaliação da aprendizagem: estranhamentos e descaminhos na formação de professores", de Luiz Antonio Saléh Amado; e "Jogos eletrônicos e educação: adolescentes e novas formas de construção do conhecimento", de Eloiza Oliveira.

Falemos de cada um deles...

No texto "Diálogos e interfaces das políticas sociais com a educação pública", Eveline Algebaile e Ney Luiz Teixeira de Almeida discutem as relações entre políticas sociais e educação pública, no Brasil, considerando a história dessas políticas e de suas relações, bem como questões e práticas mais recentes, relacionadas ao uso da escola como base de realização de programas focais e à crescente organização intersetorial de políticas. Considerando que as relações entre os diferentes setores de políticas sociais e entre os campos profissionais correlatos são marcadas por disputas de autoridade e de direção que reforçam segmentações, estranhamentos e conflitos, são discutidos os desafios contemporâneos implicados com a formulação, implementação, atuação profissional e pesquisa em políticas públicas.

Gaudêncio Frigotto, no capítulo "Cotas para alunos oriundos da rede pública de ensino público e para pretos e pardos", assinala que as cotas explicitam o avanço político de uma sociedade que admite uma estrutura econômica que produz e reproduz a desigualdade de classes e a desigualdade racial. E, ainda, que, diante da realidade desigual e violenta da nossa sociedade, o desafio é buscar compreender as determinações que produzem esta realidade como condição de poder alterá-la, e não nos limitarmos à antinomia do contra ou a favor. Ao longo do texto, o autor discute os caminhos para se entender as relações, as práticas, os interesses e os conflitos sociais em torno das cotas e, por fim, tece algumas considerações sobre as implicações, riscos e responsabilidade da universidade em face desta conquista.

No texto "Práticas pedagógicas e avaliação da aprendizagem: estranhamentos e descaminhos na formação de professores", Luiz Antonio Saléh Amado centra sua discussão nos dispositivos pedagógicos que contribuem para a formação dos professores, apontando o caráter naturalizado assumido por certas práticas. Neste sentido, propõe o exercício de estranharmos as práticas e os dispositivos pedagógicos instrumentalizados hoje, colocando em questão as racionalidades que os sustentam e os efeitos que produzem. A avaliação da aprendizagem se destaca dentre os dispositivos pedagógicos graças ao seu potencial deflagrador das experiências de si. Que outras práticas podem funcionar por meio da avaliação da aprendizagem? Ou ainda, que outras experiências ela pode proporcionar? Questões como estas orientam a utilização deste dispositivo com vistas a intervir na formação de professores, buscando práticas que ampliem as margens de liberdade nos processos de formação.

Finalmente, no capítulo "Jogos eletrônicos e educação: adolescentes e jovens diante de novas formas de construção da subjetividade e do conhecimento", Eloiza Oliveira apresenta bases teóricas para a articulação de três temas: os jogos eletrônicos, a aprendizagem e as novas possibilidades de construção do conhecimento. Prosseguindo 
nos acenos otimistas do futuro, do "campo que cheira a primavera", trata do brincar e do jogo, inerentes à natureza do homem, parte integrante da experiência humana no mundo e elemento fundamental das práticas sociais. Essa experiência se funde às tecnologias de informação e comunicação por meio dos jogos eletrônicos e da gamificação, "estratégia de aplicação de jogos para atividades non-game, influenciando e modificando comportamentos". Aborda a aplicação dos jogos eletrônicos à educação e a inserção das tecnologias no que se pretende como web currículo. Finaliza com a "escuta" de adolescentes e jovens por meio de uma pesquisa da qual alguns resultados são apresentados no texto. Conclui afirmando a crença da positividade dessa cerzidura entre educação e tecnologias: "a importância dos games e seu impacto sobre a construção da subjetividade, o potencial que podem apresentar como ferramenta pedagógica e a necessidade da formação docente para a sua utilização e das demais tecnologias de informação e comunicação, tornando o ensino e a aprendizagem mais prazerosos e significativos".

E assim chegamos ao final da coletânea, afirmando, em coro com Benedetti, que...

cada pergunta tem a sua resposta

cantamos porque chove sobre o sulco

e somos militantes desta vida

e porque não podemos nem queremos

deixar que a canção se torne cinzas.

\section{NOTAS}

1. MÉSZÁROS, I. A educação para além do capital. São Paulo: Boitempo, 2005.

2. FREIRE, Paulo. Pedagogia do Oprimido. Rio de Janeiro: Paz e Terra, 2005.

3. BENEDETTI, Mario. Antologia Poética. Rio de Janeiro: Record, 1989. 